\title{
PENGETAHUAN BIOLOGI DALAM ALQURAN
}

\author{
Ojak Manurung \\ Mahasiswa Program Doktoral Universitas Islam Negeri Sumatera Utara Medan \\ ojak.manurung@yahoo.co.id
}

\begin{abstract}
Abstrak : Pengetahuan biologi merupakan suatu ilmu yang mempelajari tentang makhluk hidup. Dan obyek kajiannya yaitu manusia, hewan dan tumbuhtumbuhan. Di antara ayat-ayat yang berkaitan dengan pengetahuan biologi yaitu: Asal kejadian: QS. al-Anbiya : 30, QS. al-Nur: 45, QS. Shad: 71-72, QS. alInsan: 2, Keanekaragaman dan klasifikasi: QS. Thaha: 53, QS. al-Hajj: 5, Reproduksi/berpasang-pasangan: QS. al-Syura: 11, QS. al-Hijr: 22, QS. Yasin: 36, Zoologi invertebrata: QS. al-Ankabut: 41, QS. al-Syura: 29, Zoologi vertebrata: QS. al-Mulk: 19, Tingkah laku hewan: QS. al-Nahal: 68, Indra (kulit): QS. al-Nisa: 56, dan tubuh hewan (unta): QS. al-Ghasyiyah: 17. Dengan adanya kajian ayat-ayat yang berkaitan dengan pengetahuan biologi, jelaslah bahwa di dalam Alquran ayat-ayatnya tidak ada satupun yang menghalangi kemajuan ilmu pengetahuan, bahkan sebaliknya mendorong untuk lebih maju lagi. Hal ini sangat bermanfaat bagi manusia. Bahwa manfaat adanya pengetahuan biologi, Allah swt. menciptakan hewan untuk kepentingan manusia, sehingga manusia sangat membutuhkan hewan untuk dijadikan konsumsi
\end{abstract}

\section{Kata Kunci : Alquran, Pengetahuan Biologi}

\section{Pendahuluan}

Pengetahuan biologi merupakan suatu kajian tentang makhluk hidup. Biologi adalah cabang dari ilmu pengetahuan alam. Begitu juga dalam dasar gerakan tubuh yang bermacam-macam, baik bagi hewan, manusia maupun tumbuh-tumbuhan. ${ }^{1}$ Di mana ilmu pengetahuan alam ini basih terbagi-bagi lagi menjadi beberapa disiplin, yaitu astronomi, geologi, arkeologi, geografi, botani, zoologi, entologi, biologi dan fisika. ${ }^{2}$

Alquran sebagai pedoman umat Islam dalam menjalani kehidupan tidak hanya memuat hal-hal yang berkaitan dengan keakhiratan saja, namun secara umum Alquran merupakan sumber rujukan berbagai macam permasalahan yang

\footnotetext{
${ }^{1}$ Al-Allamah Abdurrahman bin Muhammad bin Khaldun, Mukaddimah Ibnu Khaldun, terj. Masturi Irham dkk (Jakarta: Pustaka al-Kautsar, cet. 3, 2013), h. 913.

${ }^{2}$ Varia Winansih, Pendidikan Ilmu-Ilmu Kealaman Dalam Hadis, dalam Hasan Asari, Hadis-Hadis Pendidikan Sebuah penelusuran Akar-Akar ilmu Pendidikan Islam (Bandung: Citapustaka Media Perintis, cet. 1, 2008), h. 115.
} 
ada. $^{3}$ Termasuk di antaranya tentang kajian pengetahuan biologi. Pengetahuan biologi dengan menggunakan pendekatan tafsir tematik atau metode Maudhu'iy, menurut M. Quraish Shihab mempunyai dua pengertian, yaitu:

1. Penafsiran menyangkut satu surat dalam Alquran dengan menjelaskan tujuan-tujuannya secara umum dan merupakan tema sentralnya, serta menghubungkan persoalan-persoalan yang beraneka ragam dalam surat tersebut antara satu dan lainnya dan juga dengan tema tersebut dengan berbagai masalahnya merupakan satu-kesatuan yang tidak terpisahkan.

2. Penafsiran yang bermula dari menghimpun ayat-ayat Alquran yang membahas satu masalah tertentu dari berbagai ayat atau surat Alquran dan yang sedapat mungkin diurut sesuai dengan urutan turunnya, kemudian menjelaskan pengertian menyeluruh dari ayat-ayat tersebut, guna menarik petunjuk Alquran secara utuh tentang masalah yang dibahas. ${ }^{4}$

\section{Pembahasan}

\section{Pengertian Biologi Menurut Bahasa (Lughawi)/Etimologi.}

Yang dimaksud dengan biologi terdiri dari dua suku kata, yakni bio (alam kehidupan) termasuk di dalamnya tumbuh-tumbuhan, binatang, alam kehidupan yang diam dan manusia itu sendiri. sedangkan yang dimaksud dengan logi berasal dari bahasa Yunani atau dikenal dengan logos, yakni 'ilmu'. Jadi, secara komprehensif yang dimaksud dengan biologi adalah ilmu yang mempelajari seluruh kehidupan makhluk Allah SWT. yang ada di muka bumi ini.

Sedangkan pengetahuan biologi, secara etimologinya berasal dari kata pengetahuan dan kata biologi itu sendiri. Kata pengetahuan yaitu segala sesuatu yang diketahui. ${ }^{5}$ Sedangkan kata biologi adalah ilmu tentang keadaan dan sifat

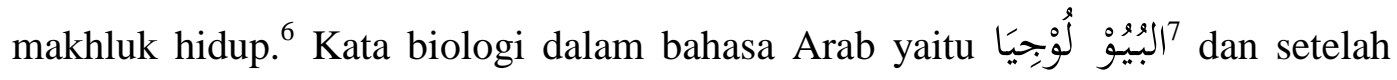

\footnotetext{
${ }^{3}$ M. Quraish Shihab, Membumikan Alquran Fungsi dan peran Wahyu Dalam Kehidupan Masyarakat (Bandung: Mizan, Edisi 2, Cet. 1, 2013), h. 88.

${ }^{4}$ Ibid. h. 111.

${ }^{5}$ Departemen Pendidikan Nasional, Kamus Besar Bahasa Indonesia Pusat Bahasa (Jakarta: Gramedia, edisi 4, cet. 1, 2008), h. 1377.

${ }^{6}$ Ibid, h. 197.
} 
dilihat dalam kitab فَتْحُ الرَّحْمَنِ لِطَلَبْ آََباتِ القُرْاَنِ ternyata tidak ditemui kata biologi. Oleh karena itu dapat disimpulkan bahwa kata biologi tidak ada dijumpai dalam Alquran. Dengan demikian, karena pengetahuan biologi adalah pengetahuan yang berkaitan dengan makhluk hidup, maka di sini dapat dikemukakan ayat-ayat yang berkaitan ataupun yang sejalan dengan pengertian pengetahuan biologi.

\section{Pengertian Biologi Menurut Istilah (Terminologi)}

Yang dimaksud dengan biologi secara istilah atau terminologi adalah mengkaji semua makhluk hidup, tidak hanya tumbuhan dan hewan yang hidup di muka bumi ini, akan tetapi tumbuhan dan hewan yang hidup di masa lampau bahkan di tempat-tempat lain jika mungkin ada kehidupan. Penggunaan Istilah biologi pertama kali tercatat pada tahun 1736 yaitu digunakan oleh Linnaeus dalam karyanya yang berjudul Bibliotheca Botanica. Namun pengkajian ilmu yang berkaitan tentang alam sudah terlebih dahulu ada sejak masa lampau.

\section{Term-term Pengetahuan Biologi dalam Alquran}

Di dalam Alquran banyak dijumpai ayat-ayat yang berkaitan dengan pengetahuan biologi. Namun dalam makalah ini hanya mengupas beberapa ayat saja di antaranya tentang:

a. Asal kejadian: QS. al-Anbiya : 30, QS. al-Nur: 45, QS. Shad: 71-72, QS. al-Insan: 2.

b. Keanekaragaman dan klasifikasi: QS. Thaha: 53, QS. al-Hajj: 5.

c. Reproduksi/berpasang-pasangan: QS. al-Syura: 11, QS. al-Hijr: 22, QS. Yasin: 36.

d. Zoologi invertebrata: QS. al-Ankabut: 41, QS. al-Syura: 29.

e. Zoologi vertebrata: QS. al-Mulk: 19.

f. Tingkah laku hewan: QS. al-Nahal: 68.

g. Indra (kulit): QS. al-Nisa: 56.

h. Tubuh hewan (unta); Qs;al-Ghassyiyah: 17.

${ }^{7}$ A. Thoha Husein Almujahid \& Atho'illah Fathoni Alkhalil, Kamus Akbar Bahasa Arab (Indonesia-Arab),(Jakarta: Gema Insani, 2013), h. 184. 


\section{Penafsiran Ayat yang Berkaitan Dengan Pengetahuan Biologi Menurut Tafsir Klasik/Tradisional}

a. Dalam tafsir al-Maraghi (tafsir klasik/tradisional) yang berjudul alMaraghi, Ahmad Mustafa. 1946. tafsir al-Maraghi, Kairo: Bab alHalabi. Jld. 1. dan lihat juga dalam buku Hasan Zaini, Tafsir Tematik Ayat-ayat Kalam Tafsir Al-Maraghi, (Jakarta: Pedoman Ilmu Jaya, 1997), h. 383. dikatakan bahwa ;

1) Penciptaan manusia merupakan ragam dari manusia, sehingga manusia itu dalam konteks ke alaman merupakan rangkaian satu tautan yang saling berhubungan;

2) Penciptaan alam (termasuk di dalamnya manusia) merupakan konsistensi alam tersebut memuat zat Allah swt;

3) Kepada manusia Allah swt. mengamanahkan alam semesta ini untuk dikelola dan dimanfaatkan bagi kemashlahatan seluruh makhluk;

4) Untuk berkemampuan mengelola dan memanfaatkan alam semesta, kepada manusia, Allah swt. anugerahkan aql dan aql ini tidak diberikan-Nya, kecuali hanya kepada manusia. Karena itu, manusia dikeluarkan dari defenisi alam semesta. Dengan demikian, penggunaan terma alam semesta hanya merujuk pada pengertian alam semesta dalam pengertian jagat raya;

5) Dalam Alquran, pengertian alam semesta dalam arti jagat raya bisa dipahami dari terma al-samáwát wa al-ardi wa má baynahuma. Ungkapan ini berulang sebanyak 20 kali dan tersebar pada 15 surat

Hal-hal di atas sesuai dengan tafsir al-Maraqhi, yang tertera dalam surat yasin ayat 36, surat as-Syura ayat 11 dan surat al-Hijr ayat 22

b. Kemudian dalam tafsir Fakhruddin ar-Razi (Tafsir Klasik/Tradisional) yang berjudul Tafsir al-Kabir. Beirut: Dar al-Fikr, 1981, Juz I dikatakan bahwa; 
1) Alam yang diciptakan oleh Allah swt. tidak terlepas dari apa yang diciptakannya untuk manusia. sebab hal ini berkaitan dengan mutu simboisis.

2) Alam yang terbentang oleh Allah swt. diisinya dengan makhlukmakhluk hidup

3) Alam yang dimuat oleh Allah swt. merupakan bukti bahwa Allah swt. memiliki keutamaan dalam penciptaan, dan bukan hanya menciptakan tapi juga mengembangkan dan menjaganya dengan baik, sebagaimana Allah menunjukkannya dalam surat QS. al-Syura: 29:

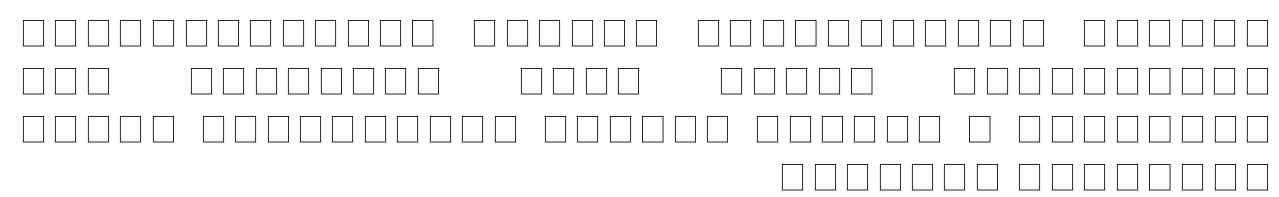

Di antara (ayat-ayat) tanda-tanda-Nya ialah menciptakan langit dan bumi dan makhluk-makhluk yang melata yang Dia sebarkan pada keduanya. dan Dia Maha Kuasa mengumpulkan semuanya apabila dikehendaki-Nya.

Tafsiran di atas mengungkapkan bahwa apa yang disebarkan oleh Allah swt. adalah hewan-hewan yang melata, artinya makhluk hidup yang saling berkaitan atau bergantung kepada makhluk lainnya. Kemudian dalam tafsir Fakhruddin ar-Razi tentang ayat di atas sesuai dengan surat Qs.an-Nahl; 68 dan surat al-Mulk ayat 19 dan surat alGhassyiyah ayat 17 .

\section{Penafsiran Ayat yang Berkaitan Dengan Pengetahuan Biologi Menurut Tafsir Modern}

Ayat-ayat yang berkaitan dengan pengetahuan biologi di antaranya:

Asal kejadian tentang alam beserta isinya, yakni dalam surat al-Anbiya ayat 30

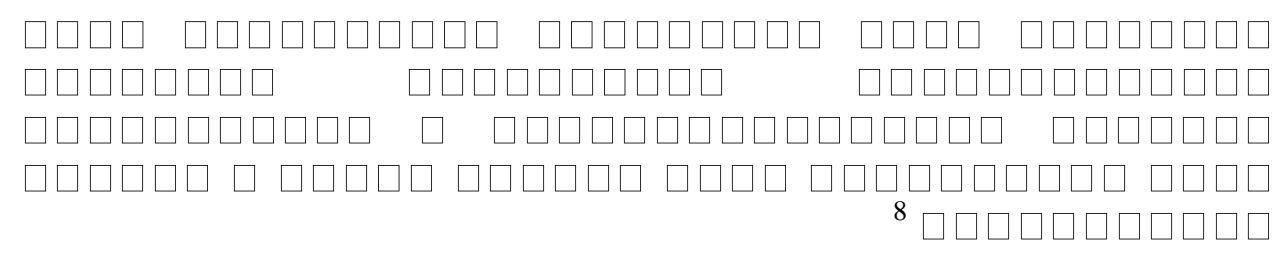

\footnotetext{
${ }^{8}$ QS. al-Anbiya : 30.
} 
Dan Apakah orang-orang yang kafir tidak mengetahui bahwasanya langit dan bumi itu keduanya dahulu adalah suatu yang padu, kemudian Kami pisahkan antara keduanya. dan dari air Kami jadikan segala sesuatu yang hidup. Maka Mengapakah mereka tiada juga beriman?

1) Menurut M. Quraish Shihab (M. Quraish Shihab, Tafsir al-Misbah Pesan, Kesan, dan Keserasian Alquran Volume 8 Cet.V (Jakarta: Lentera Hati, 2012), dalam memahami ayat di atas bahwa langit dan bumi tadinya merupakan satu gumpalan yang terpadu. Hujan tidak turun dan bumi pun tidak ditumbuhi pepohonan, kemudian Allah membelah langit dan bumi dengan jalan menurunkan hujan dari langit dan menumbuhkan tumbuh-tumbuhan di bumi. selanjutnya segala makhluk yang hidup membutuhkan air atau pemeliharaan kehidupan segala sesuatu adalah dengan air dijadikan dari cairan yang terpancar dari sulbi (sperma) segala yang hidup yakni dari jenis binatang. Air merupakan komponen terpenting dalam pembentukan sel yang merupakan satuan bangunan pada setiap makhluk hidup, baik hewan maupun tumbuhan. ${ }^{9}$

Dalam surat an-Nur ayat 45, surat Thaha ayat 53 dan surat al-Hajj ayat 5, menurut para ilmuan sains dan teknologi serta mufassir lain, (yakni As-Suyuthi,Jalaluddin, al-Durr al-Mantsur fi al-Tafsir al-Ma'tsur. Bairut: Darr al- Fikr, 1994) ada tiga pendapat yang terkait dengan kehidupan yang dimulai dari air, baik itu dari tingkat keanekaragaman dan klasifikasinya, yaitu:

a) Kehidupan dimulai dari air dalam hal ini laut. Teori ini percaya bahwa kehidupan muncul dari rantai reaksi kimia yang panjang dan komplek. Rantai kimia ini dipercaya dimulai dari dalam air laut, karena kondisi atmosfer saat itu belum berkembang menjadi kawasan yang dapat dihuni makhluk hidup karena radiasi ultra violet yang terlalu kuat.

${ }^{9}$ M. Quraish Shihab, Tafsir al-Misbah Pesan, Kesan, dan Keserasian Alquran Volume 8 Cet.V (Jakarta: Lentera Hati, 2012), h. 41. 
b) Peran air bagi kehidupan dapat juga diekspresikan dalam bentuk bahwa semua benda hidup, terutama kelompok hewan, berasal dari cairan sperma.

c) Bahwa air merupakan bagian yang penting agar makhluk dapat hidup. Pada kenyataannya, memang sebagian besar bagian tubuh makhluk hidup terdiri dari air. ${ }^{10}$

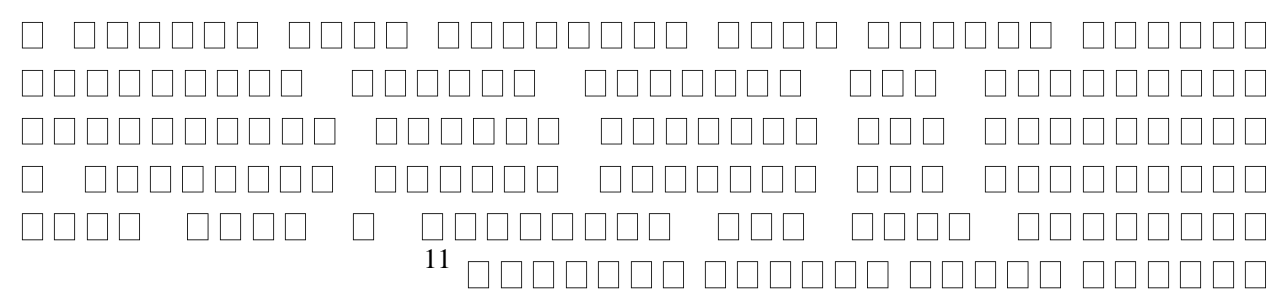

Dan Allah telah menciptakan semua jenis hewan dari air, Maka sebagian dari hewan itu ada yang berjalan di atas perutnya dan sebagian berjalan dengan dua kaki sedang sebagian (yang lain) berjalan dengan empat kaki. Allah menciptakan apa yang dikehendaki-Nya, Sesungguhnya Allah Maha Kuasa atas segala sesuatu.

2) Dalam surat al-Shad ayat 71-72, menurut Hamka (Hamka, Tafsir AlAzhar. juz I-II (Jakarta; PT Pustaka Panjimas 1983), dalam memahami ayat tersebut bahwa Allah telah menciptakan semua jenis hewan dari air yang memancar sebagaimana Dia menciptakan tumbuhan dari air yang tercurah. Lalu Allah menjadikan hewan-hewan itu ada yang berjalan di atas perutnya, seperti buaya, ular, dan hewan melata lainnya, dan sebagian berjalan dengan dua kaki, seperti manusia, burung, sedangkan yang lain berjalan dengan empat kaki, seperti sapi, kambing, dan lain-lain, dan ada juga yang berjalan dengan menggunakan lebih dari empat kaki, seperti kalajengking, laba-laba, dan lain-lain. ${ }^{12}$

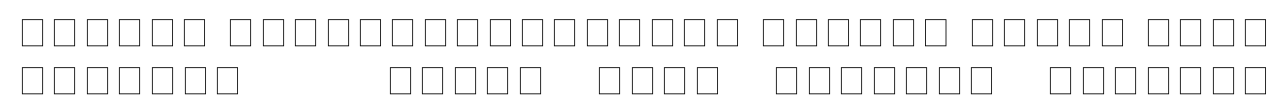

${ }^{10}$ Akhsin Sakho Muhammad dkk, Alquran Dan Tafsirnya (Jakarta: Widya Cahaya, Jilid 6, 2011), h. 251. lih. Juga tafsir Jalaluddin as-Suyuthi, al-Durr al-Mantsur fi al-Tafsir al-Ma 'tsur (Bairut: Darr al- Fikr, 1994), h. 209.

${ }^{11}$ QS. al-Nur: 45.

${ }^{12}$ Hamka, Tafsir Al-Azhar. juz I-II (Jakarta; PT Pustaka Panjimas 1983), h. 301. 


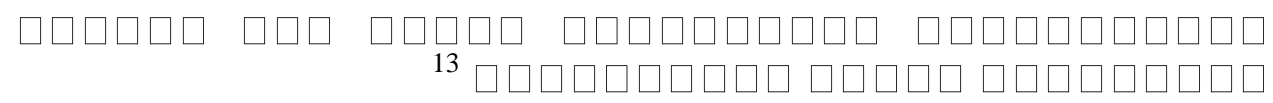
(Ingatlah) ketika Tuhanmu berfirman kepada Malaikat: "Sesungguhnya aku akan menciptakan manusia dari tanah". Maka apabila telah Kusempurnakan kejadiannya dan Kutiupkan kepadanya roh (ciptaan)Ku; Maka hendaklah kamu tersungkur dengan bersujud kepadaNya".

3) Menurut Tafsir Inspirasi (Tafsir inspirasi karangan Zainal Arifin Zakaria, Cet. II (Jakarta: PT Ikrar Mandiriabadi, 2013, dan diterbitkan juga oleh Duta Azhar Medan tahun 2013), dikatakan bahwa dalam surat al-Insan ayat 2, manusia itu berasal dari tetesan mani (sperma) yang dimasukkan ke dalam rahim ibu, sehingga terjadilah proses pembentukan manusia, dari zigot sampai kepada bentuk segumpulan darah, tulang, daging dan kulit. ${ }^{14}$

4) Menurut Tafsir al-Ahkam (tafsir Al-Ahkam karangan Syekh Abdul Halim Hasan Binjai yang berjudul Tafsir Al-Ahkam Cet.I Tahun 2006), dalam memahami surat al-Insan ayat 2, yakni tentang peristiwa Adam bersama malaikat dan iblis. Di mana Adam diciptkaan dari tanah yang bercampur dengan air. ${ }^{15}$ Berdasarkan kajian ilmiah bahan penciptaan manusia adalah tanah, persisnya yaitu tanah liat. Istilah liat biasa dipakai untuk menamai butiran tanah dengan ukuran yang paling kecil, diameter di bawah 0,5 mikron $(1 / 200 \mathrm{~mm})$. Istilah liat juga biasa dipakai untuk menamai jenis mineral pembentuk butiran tanah paling kecil. Karena ukurannya yang kecil, liat bila dimasukkan kedalam air akan bersifat koloidal/tidak melarut tetapi tersebar merata dan sulit dipisahkan dari air. ${ }^{16}$

Dalam tafsir inspirasi, dalam memahami ayat di atas (surat al-Insan ayat 2) serta surat al-Mu'minun ayat 12 menjelaskan proses awal penciptaannya serta tujuannya. Semua anak cucu Adam dan Hawa kecuali Isa dari setetes mani yang

\footnotetext{
${ }^{13}$ QS. Shad: 71-72.

${ }^{14}$ Zainal Arifin Zakaria, Tafsir Inspirasi. Cet. II (Jakarta: PT Ikrar Mandiriabadi, 2013, dan diterbitkan juga oleh Duta Azhar Medan tahun 2013), h. 369.

${ }^{15}$ Syekh Abdul Halim Hasan Binjai, Tafsir Al-Ahkam. Cet.I (Tahun 2006), h. 237.

${ }^{16}$ Akhsin Sakho Muhammad dkk, Alquran Dan Tafsirnya (Jakarta: Widya Cahaya, Jilid 8, 2011), h. 397.
} 
bercampur, yaitu dari sperma laki-laki dan indung telur wanita,yang tujuan penciptaannya adalah untuk mengujinya dengan berbagai perintah dan larangan. ${ }^{17}$

\section{Asbab an-Nuzul dan Munasabah}

Asbab an-Nuzul dan Munasabahnya dinarasikan sebagai berikut;

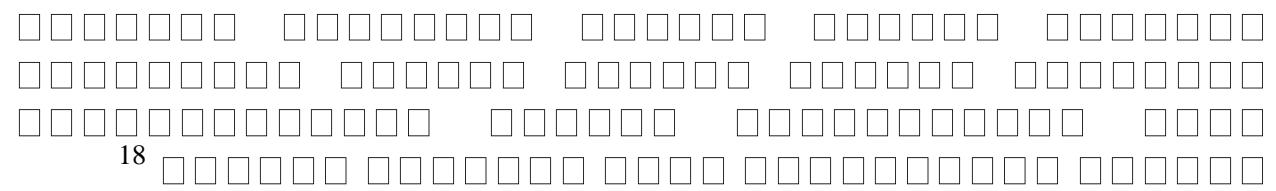

Yang telah menjadikan bagimu bumi sebagai hamparan dan yang telah menjadikan bagimu di bumi itu jalan-jalan, dan menurunkan dari langit air hujan. Maka Kami tumbuhkan dengan air hujan itu berjenis-jenis dari tumbuh-tumbuhan yang bermacam-macam.

Allah menempatkan manusia di bumi dengan menghamparkannya agar mereka dapat menikmati hidup dan berbekal guna kehidupan akhiratnya, serupa dengan bayi yang ditempatkan dalam buaian dan didik guna meraih kehidupan yang lebih mulia dan tinggi. Allah menjadikan manusia di bumi ini agar ia menyadari bahwa ada jarak antara ia dan tujuan hidupnya. Ada jalan yang harus ditempuhnya guna mencapai tujuan hidup itu, yakni pendekatan diri kepada Allah dan upaya masuk ke hadirat-Nya, sebagaimana halnya ia menempuh jalan-jalan di permukaan bumi ini untuk mencapai arah dan tujuan yang ditujunya. Allah menurunkan air dari langit berupa hujan dan juga mata air dan sungai-sungai serta lautan, lalu ditumbuhkan dari air itu aneka macam dan jenis tumbuhan lalu Allah memberi hidayah kepada manusia dan binatang untuk memanfaatkan buahbuahan dan tunmbuh-tumbuhan itu untuk kelanjutan hidupnya, sebagaimana terdapat juga isyarat bahwa Allah memberikan hidayah kepada langit guna menurunkan hujan, dan hidayah buat hujan agar turun tercurah, dan untuk tumbuh-tumbuhan agar tumbuh berkembang. ${ }^{19}$

Tuhanlah yang menurunkan hujan sehingga tumbuhnya tanam-tanaman dan buah-buahan yang bermacam-macam cita rasanya, ada yang masam, ada yang

${ }^{17}$ M. Quraish Shihab, Tafsir al-Misbah Pesan, Kesan, dan Keserasian Alquran (Jakarta: Lentera Hati, Volume 14, Cet. 5, 2012), h. 565.

${ }^{18}$ QS. Thaha: 53.

${ }^{19}$ M. Quraish Shihab, Tafsir al-Misbah Pesan, Kesan, dan Keserasian Alquran (Jakarta: Lentera Hati, Volume 7, Cet. 5, 2012), h. 605. 
manis, bermacam ragam jenis dan manfaatnya. Ada yang layak untuk manusia, dan ada yang baik untuk binatang yang kesemuanya itu menunjukkan atas besarnya karunia dan banyaknya nikmat yang dilimpahkan Allah keapda semua hamba-Nya. ${ }^{20}$

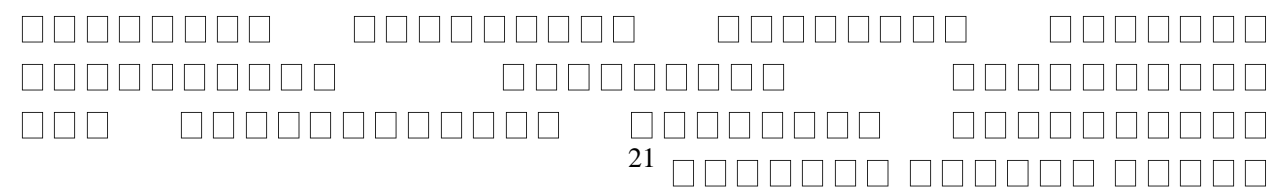

... Dan kamu Lihat bumi ini kering, kemudian apabila telah Kami turunkan air di atasnya, hiduplah bumi itu dan suburlah dan menumbuhkan berbagai macam tumbuh-tumbuhan yang indah.

Ayat di atas menurut M.Quraish Shihab dalam asbab an-Nuzul dan munasabahnya memberikan contoh bahwa setiap orang dapat melihat bumi ini kering kerontang gersang dan mati, maka apabila telah diturunkan air di atasnya maka terlihat tanda-tanda kehidupan padanya, yakni dia bergerak dan mengembang permukaannya, meninggi akibat air dan udara yang menyelanyelanya dan akhirnya menumbuhkan berbagai jenis tumbuhan yang indah, memukau dan membuat senang siapa saja yang melihatnya. ${ }^{22}$

Semakin lama tumbuh-tumbuhan itu semakin besar, bahkan daun-daunnya telah menutupi permukaan bumi yang semulanya tandus, dengna warna warni yang beraneka ragam, ada yang hijau, ada yang keputih-putihan, ada yang merah dan sebagainya. Perpaduan warna-warni daun-daunan itu sangat indah dan menakjubkan dan semakin indah oleh warna-warni bunga-bungaan yang bermacam corak warnanya. Maka permukaan bumi yang dahulunya tandus telah berubah menjadi hamparan pohon-pohon dan tanam-tanaman yang beraneka ragam warnanya. ${ }^{23}$

M.Quraish Shihab menyatakan reproduksi/berpasang-pasangan dalam surat al-Syura ayat 11 tentang asbab an-Nuzul dan Munasabahnya, bahwa Dia (Allah) telah menjadikan bagi kamu dari jenis kamu sendiri pasangan-pasangan, baik sebagai lelaki (suami) maupun perempuan (isteri), dan menjadikan pula dari

\footnotetext{
${ }^{20}$ Muhammad, Alquran ..., Jilid 8, h. 150.

${ }^{21}$ QS. al-Hajj: 5.

${ }^{22}$ Shihab, Tafsir ..., Volume 8, h. 155.

${ }^{23}$ Muhammad, Alquran..., Jilid 6, h. 356.
} 
jenis binatang ternak pasangan-pasangan buat masing-masing binatang, baik jantan maupun betina, sehingga kamu dan binatang-binatang itu dapat melanjutkan keturunan. Dengan pengaturan-Nya itu Dia terus menerus mengembangbiakkan kamu, yakni menjadikan kamu banyak serta merasa bahagia di dalamnya. ${ }^{24}$ Jadi, di sana ada kesatuan penciptaan yang membuktikan kesatuan pola, kehendak, dan tujuan. ${ }^{25}$

Model penciptaan berpasang-pasangan antara laki-laki dan perempuan terlihat jelas pada makhluk hidup dari manusia hingga hewan dan tumbuhan. Jenis betina masing-masing spesies organisme ini memiliki alat-alat reproduksi yang salah satunya disebut dengan istilah Ovary (indung telur). Alat-alat reproduksi ini dianugerahi kemampuan yang luar biasa oleh Allah untuk menghasilkan sel-sel reproduksi wanita yang disebut Ovum. Di sisi lain, jenis jantan masing-masing spesies ini juga memiliki alat-alat reproduksi yang serupa, salah satunya disebut testis yang dianugerahi kemampuan yang luar biasa oleh allah untuk memproduksi sel-sel reproduksi pria yang disebut sperma. ${ }^{26}$ Tumbuh-tumbuhan pun memiliki pasangan-pasangan guna pertumbuhan dan perkembangannya. Sebelumnya, manusia tidak mengetahui bahwa tumbuh-tumbuhan juga memiliki perbedaan kelamin jantan dan betina. Buah adalah produk akhir dari reproduksi tumbuhan tinggi.tahap ayng mendahului buah adalah bunga, yang memiliki organ jantan dan betina, yaitu benang sari dan putik. Bila tepung sari dihantarkan keputik, akan menghasilkan buah, yang kemudian tumbuh, hingga akhirnya matang dan melepaskan bijinya. Oleh sebab itu, seluruh buah mencerminkan keberadaan organ-organ jantan dan betina. Hal ini sesuai dengan surat al-Hijr ayat 22. ${ }^{27}$ Menurut M.Quraish Shihab bahwa Allah telah menghembuskan angin untuk menyuburkan, mengembangkan, dan mengawinkan tumbuh-tumbuhan.

\footnotetext{
${ }^{24}$ M. Quraish Shihab, Tafsir al-Misbah Pesan, Kesan, dan Keserasian Alquran (Jakarta: Lentera Hati, Volume 12, Cet. 5, 2012), h. 124.

${ }^{25}$ Sayyid Quthb, Tafsir fi Zhilalil Quran di Bawah Naungan Alquran (Jakarta: Gema Insani Press, Jilid 10, cet. 2, 2008), h. 192.

${ }^{26}$ Zaglul al-Najjar, Sains dalam Hadis Mengungkap Fakta Ilmiah dai Kemukjizatan Hadis Nabi, terj. Zainal Abidin dkk (Jakarta: Amzah, cet. 1, 2011), h. 438.

${ }^{27}$ Akhsin Sakho Muhammad dkk, Alquran Dan Tafsirnya (Jakarta: Widya Cahaya, Jilid 9, 2011), h. 31.
} 
Pertumbuhan, perkembangan dan perkawinan tumbuh-tumbuhan dengan perantaraan angin itu maksudnya:

a. Allah menghembuskan angin yang membawa awan yang mengandung hujan. Kemudian hujan turun membasahi permukaan bumi, sehingga tanah yang semula kering menjadi subur. Tumbuh-tumbuhan menjadi tumbuh dan berkembang lalu berbunga, berputik, dan berbuah.sebagaian buahnya dapat dimanfaatkan oleh manusia dan binatang, sedang sebagian yang lain tumbuh dan berkembang lagi untuk melanjutkan keturunan dan mempertahankan jenisnya dari kepunahan.

b. Allah menghembuskan angin yang menerbangkan tepung sari dari beragam bunga. Maka hinggaplah tepung sari jantan pada putik bunga sehingga terjadilah perkawinan yang memunculkan bakal buah, dan buah-buahan menjadi masak terasa yang lezat dan nikmat bagi manusia serta bijinya dapat tumbuh dan berbuah pula di tempat lain.

c. Hembusan angin dapat membersihkan debu yang hinggap pada batang dan daun tumbuh-tumbuhan, sehingga tumbuh-tumbuhan itu mudah bernafas dan menjadi besar, serta daunnya mudah menyerap sinar matahari yang menambah kekokohan dan kesuburannya. ${ }^{28}$

Namun menurut Hamka dalam tafsir Al-Azharnya melalui asbab anNuzul dan Munasabhnya, bahwa perkawinan yang dilakukan angin itu mengakibatkan turunnya hujan, bukan mengakibatkan tumbuhnya tumbuhan. ${ }^{29}$

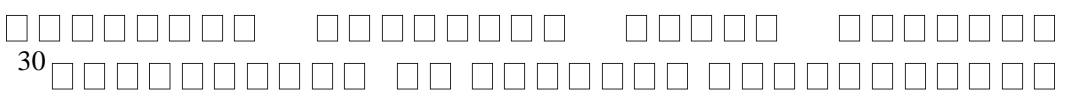

Maha suci Tuhan yang telah menciptakan pasangan-pasangan semuanya, baik dari apa yang ditumbuhkan oleh bumi dan dari diri mereka maupun dari apa yang tidak mereka ketahui.

${ }^{28}$ Akhsin Sakho Muhammad dkk, Alquran Dan Tafsirnya (Jakarta: Widya Cahaya, Jilid 5, 2011), h. 228-230.

${ }^{29}$ Hamka, Tafsir Al-Azhar. juz I-II (Jakarta; PT Pustaka Panjimas 1983), h. 203.

${ }^{30}$ QS. Yasin: 36. 
Menurut Hamka, bahwa Dialah Tuhan yang menciptakan pasanganpasangan semuanya, pasangan yang berfungsi sebagai pejantan dan betina, baik dari apa yang ditumbuhkan oleh bumi, seperti kurma dan anggur, dan demikian jugadari diri mereka sebagai manusia, di mana mereka terdiri dari lelaki dan perempuan, dan demikian pula dari apa yang tidak atau belum kereka ketahui, baik makhluk hidup maupun benda tak bernyawa. ${ }^{31}$

Pada ayat ini diterangkan tanda-tanda kekuasaan dan kebesaran Allah, yang terdapat dalam pasangan-pasangan yang telah diciptakan-Nya, yaitu:

1) Benda-benda yang ditumbuhkan-Nya di bumi yang telah diketahui manusia seperti tumbuh-tumbuhan dan sebagainya.

2) Pada diri mereka sendiri, seperti adanya jenis laki-laki dan jenis perempuan. Dari hubungan kedua jenis itu lahirlah keturunanketurunan mereka.

3) Hal-hal yang belum diketahui manusia. Ilmu allah amat luas dan tidak terhingga, sedangkan yang diketahui manusia hanyalah sebagian kecil saja. Mengenai pasangan, juga terdapat hal-hal yang belum terungkap oleh manusia. ${ }^{32}$

Dalam tafsir Al-Azhar karangan Buya Hamka yang berjudul Tafsir AlAzhar juz I-II penerbit PT Pustaka Panjimas, Jakarta tahun 1983 juga dikatakan bahwa zoologi invertebrata terdapat dalam Alquran, yakni sebagai berikut;

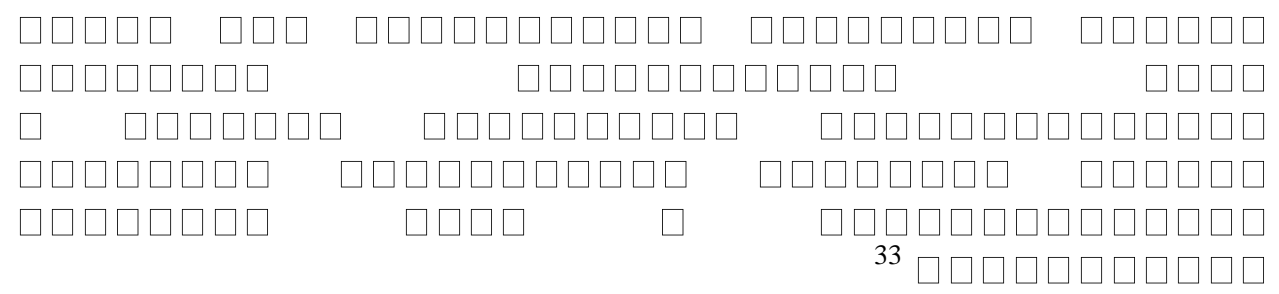

Perumpamaan orang-orang yang mengambil pelindung-pelindung selain Allah adalah seperti laba-laba yang membuat rumah. dan Sesungguhnya rumah yang paling lemah adalah rumah laba-laba kalau mereka mengetahui.

Menurut Hamka, bahwa Laba-laba adalah serangga besar berkaki delapan berwarna abu-abu kehitam-hitaman. Serangga ini biasa menjalin jaring dari benang sutera yang dihasilkan dari perutnya sebagai sarang sekaligus perangkap

\footnotetext{
${ }^{31}$ Hamka, Tafsir, h. 203

${ }^{32}$ Ibid, h. 210.

${ }^{33}$ QS. al-Ankabut: 41.
} 
mangsa. ${ }^{34}$ Sarang laba-laba itu ibarat dari suatu bangunan rumah yang sangat rapuh. $^{35}$

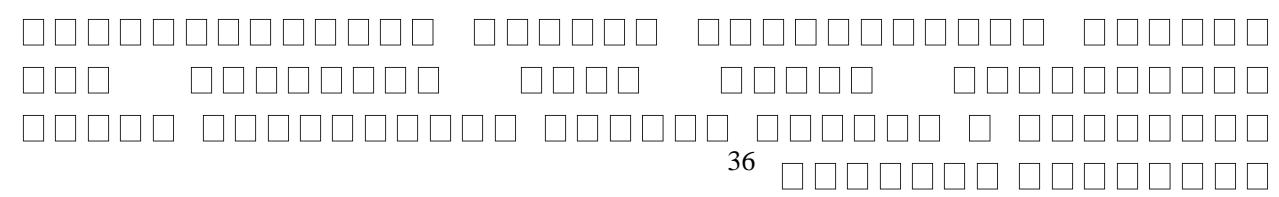

Di antara (ayat-ayat) tanda-tanda-Nya ialah menciptakan langit dan bumi dan makhluk-makhluk yang melata yang Dia sebarkan pada keduanya. dan Dia Maha Kuasa mengumpulkan semuanya apabila dikehendaki-Nya.

Kata dabbah dari segi bahasa berarti semua binatang yang memiliki nyawa, berakal atau tidak berakal, lelaki/jantan atau perempuan/betina. Dan tidak masuk dalam kategori ini malaikat, jin, atau arwah. Dan manusia boleh jadi masuk dalam kategori ini dalam kedudukannya sebagai binatang yang berakal. ${ }^{37}$ Namun ada sebagian ahli tafsir memasukkan jin ke dalam jenis makhluk yang melata juga. ${ }^{38}$

Kemudian dalam surat al-Mulk ayat 19 dikatakan;

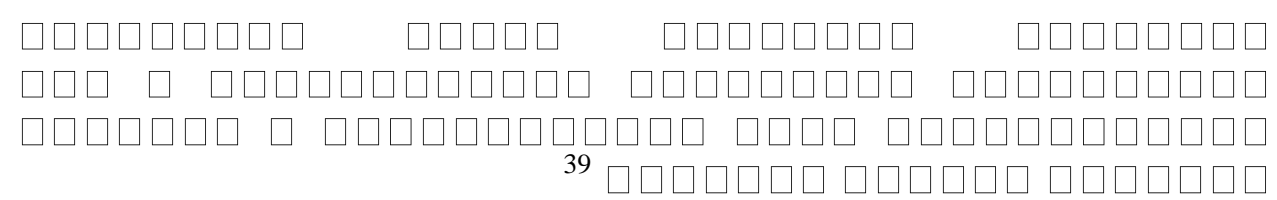

Dan Apakah mereka tidak memperhatikan burung-burung yang mengembangkan dan mengatupkan sayapnya di atas mereka? tidak ada yang menahannya (di udara) selain yang Maha Pemurah. Sesungguhnya Dia Maha melihat segala sesuatu.

Ayat di atas menggunakan bentuk kata yang menunjukkan pelaku ketika menguraikan berkembang lebarnya sayap-sayap burung. Hal ini mengisyaratkan bahwa untuk terbang burung tidak perlu mengatup-atupkan sayap. Ia hanya membutuhkan hal itu pada saat ia akan bergerak menuju arah tertentu. kondisi pergerakan sayap bukanlah sesuatu yang terjadi terus menerus. ${ }^{40}$ Tulang burung

\footnotetext{
${ }^{34}$ Hamka, Tafsir Al-Azhar, juz I-II (Jakarta; PT Pustaka Panjimas, 1983), h. 109.

${ }^{35}$ Akhsin Sakho Muhammad dkk, Alquran Dan Tafsirnya Jilid VII (Jakarta: Widya Cahaya, 2011), h. 405 .

${ }^{36}$ QS. al-Syura: 29.

${ }^{37}$ Hamka, Tafsir, h. 110.

${ }^{38}$ Muhammad, Alquran ..., Jilid VII, h. 57.

${ }^{39}$ QS. al-Mulk: 19

${ }^{40}$ Shihab, Tafsir ..., Volume 14, h. 218.
} 
umumnya berlubang di tengahnya, dan berdinding tipis. Berat tubuh burung diletakkan di bagian tengah tubuh. Di bagian dada terdapat tulang dada yang besar yang melekat pada otot dada besar. Otot dada inilah yang menggerakkan sayap. Otot dada meliputi sekitar 25-30\% dari keseluruhan berat badan burung. ${ }^{41}$

Dalam surat an-Nahl ayat 68 dikatakan;

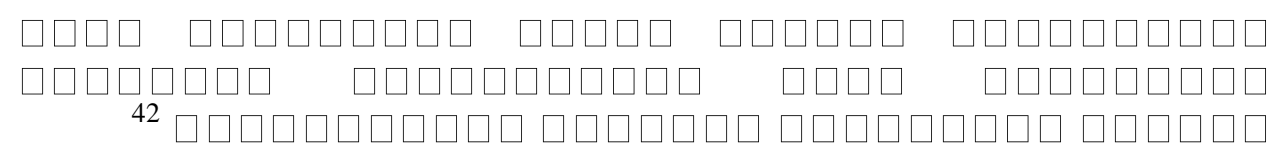

Dan Tuhanmu mewahyukan kepada lebah: "Buatlah sarang-sarang di bukit-bukit, di pohon-pohon kayu, dan di tempat-tempat yang dibikin manusia",

Lebah adalah serangga berbulu dan bersayap empat dan hidup dari madu kembang. Besarnya lebih kurang dua kali besar lalat yang umum terlihat, warna perutnya coklat kemerah-merahan. ${ }^{43}$ Kelompok lebah diperkirakan terdiri atas paling tidak 20.000 jenis. Masing-masing jenis memiliki cara sendiri-sendiri dalam membuat sarangnya. Mereka menggunakan semua sarana, mulai dari guagua yang terletak di pegunungan, lubang-lubang pada pohon tua, atau membuat sarang sendiri dan menggantungnya pada cabang pohon. ${ }^{44}$

Dalam surat al-Nisa ayat 56 dikatakan;

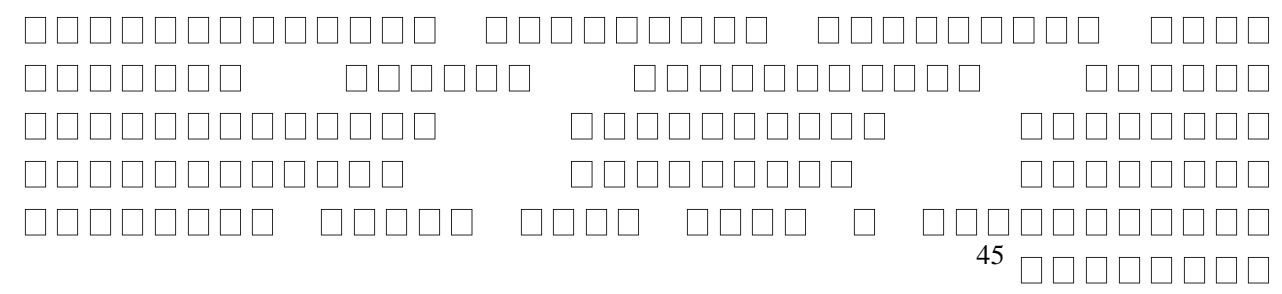

Sesungguhnya orang-orang yang kafir kepada ayat-ayat Kami, kelak akan Kami masukkan mereka ke dalam neraka. Setiap kali kulit mereka hangus, Kami ganti kulit mereka dengan kulit yang lain, supaya mereka merasakan azab. Sesungguhnya Allah Maha Perkasa lagi Maha Bijaksana.

Satu penemuan membuktikan bahwa saraf yang tersebut pada lapisan kulit merupakan yang paling sensitif terhadap pengaruh panas dan dingin. Atau dengan

\footnotetext{
${ }^{41}$ Muhammad, Alquran..., Jilid 5, h. 247.

${ }^{42}$ QS. al-Nahal: 68.

${ }^{43}$ Shihab, Tafsir ..., Volume 6, h. 645.

${ }^{44}$ Muhammad, Alquran..., Jilid 5, h. 346.

${ }^{45}$ QS. al-Nisa: 56.
} 
kata lain, kulit adalah alat perasa yang paling peka. ${ }^{46}$ Oleh karena itu, setiap kali kulit mereka hangus sampai tidak merasakan sesuatu lagi, kulit ini diganti dengan kulit yang baru yang dapat merasakan pedihnya api yang membakar. ${ }^{47}$

Setelah ditemukan mikroskop elektrik, kedokteran modern membuktikan bahwa kulit adalah tempat perasaan perih dan nyeri. Telah ditemukan juga pusatpusat syaraf di bawah lapisan kulit yang fungsinya menerima perasaan panas dan mengubahnya menjadi perasaan nyeri. ${ }^{48}$

Dalam surat QS. al-Ghassyiyah: 17;

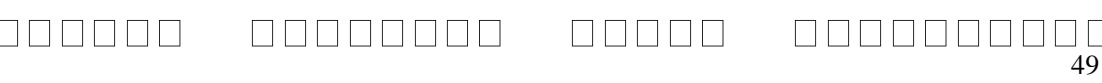

Maka Apakah mereka tidak memperhatikan unta bagaimana Dia diciptakan

Sebab turunnya ayat di atas adalah: Ibnu Jarir dan Ibnu Abi Hatim meriwayatkan dari Qatadah yang berkata, "tatkala Allah menginformasikan sifatsifat surga, orang-orang yang sesat menjadi terheran-heran. Allah lalu menurunkan ayat ini". ${ }^{50}$ Dari bentuk tubuhnya, unta memiliki potensi untuk dijadikan kenderaan di padang pasir. Matanya terletak pada bagian kepala yang agak tinggi dan agak ke belakang, ditambah dengan dua lapis bulu mata yang melindunginya dari pasir dan kotoran. Demikian juga dengan kedua lubang hidung dan telinga yang dikelilingi dengan rambut untuk maksud yang sama. Maka apabila badai pasir bertiup kencang, kedua lubang hidung itu akan tertutup dan kedua telinganya akan melipat ke tubuhnya, meski bentuknya kecil dan hampir tidak telihat. Sedangkan kakinya yang panjang adalah untuk membantu memperdepat geraknya, seimbang dengan lehernya yang panjang pula. Telapak kakinya yang lebar seperti sepatu berguna untuk memudahkannya dalam berrjalan di atas pasir yang lembut. Unta juga mempunyai daging tebal di bawah dadanya

\footnotetext{
${ }^{46}$ M. Quraish Shihab, Tafsir al-Misbah Pesan, Kesan, dan Keserasian Alquran (Jakarta: Lentera Hati, Volume 2, Cet. 5, 2012), h. 575.

${ }^{47}$ Akhsin Sakho Muhammad dkk, Alquran Dan Tafsirnya (Jakarta: Widya Cahaya, Jilid 2, 2011), h. 195.

${ }^{48}$ Nadiah Tharayyahrah, Sains Dalam Alquran, terj. M. Zaenal Arifin dkk (Jakarta: Zaman, cet. 1, 2013), h. 285.

${ }^{49}$ QS. al-Ghasyiyah : 17.

${ }^{50}$ Jalaluddin al-Suyuthi, Lubab al-Nuqul fi Asbab al-Nuzul, terj. Abdul Hayyie dkk, Sebab Turunnya Ayat Alquran (Jakarta: Gema Insani, cet. 1, 2008), h. 622.
} 
dan bantalan-bantalan pada persendian kakinya yang memungkinkannya untuk duduk di atas tanah yang keras dan panas.

Pada sisi-sisi ekornya yang panjang, terdapat bulu yang melindungi bagian-bagian belakang yang lembut dari segala macam kotoran. Pada musim dingin, unta tidak membutuhkan air. Bahkan, unta dapat bertahan tanpa minum air selama dua bulan berturut-turut apabila makanan yang dimakannya segar dna berair dan selama dua minggu berturut-turut apabila makanannya kering. Unta juga dapat menahan rasa haus saat terik musim panas selama satu atau dua minggu. Pada saat seperti itu, ia akan kehilangan lebih dari sepertiga berat badannya. Kemudian bila menemukan air, unta segera meminumnya dalam jumlah yang sangat banyak untuk mengembalikan berat badannya semula dalam waktu beberapa menit saja. Air yang diminum unta tidak disimpan di lambungnya, sebagaimana diduga orang banyak, melainkan di sela-sela badannya. Air itu digunakan dengan sangat hemat. Maka dari itu, unta sama sekali tidak pernah terengah-engah, tidak pernah bernapas dengan mulutnya, dan tidak mengeluarkan keringat dari kulitnya, kecuali dalam jumlah yang sangat sedikit. Hal ini disebabkan oleh suhu tubuhnya yang sangat rendah pada pagi hari, kemudian mulai meninggi secara perlahan-lahan lebih dari enam derajat sebelum ia perlu mengeluarkan keringat untuk menyegarkan dan menurunkan suhu badannya kembali. Meski kehilangan air dalam jumlah yang sangat banyak setelah mengalami kehausan yang sangat panjang, tekanan darah unta sama sekali tidak terpengaruh kecuali dalam batas-batas tertentu saja. Maka dari itu, unta tidak akan mati karena kehausan atau dahaga. ${ }^{51}$

Kemudian unta juga memiliki kekhasan tersendiri dibandingkan dengan binatang-binatang lainnya. Ia dengan kekuatannya yang besar dan tubuhnya yang besar dan jangkung, tetap tunduk dan penurut dituntun dan dikendalikan oleh anak kecil sekalipun. Ia yang besar manfaat dan pelayanannya terhadap manusia, tetapi tidak repot pemeliharaannya. Ia mudah digembalakan. Ia adalah binatang yang

\footnotetext{
${ }^{51}$ M. Quraish Shihab, Tafsir al-Misbah Pesan, Kesan, dan Keserasian Alquran (Jakarta: Lentera Hati, Volume 15, Cet. 5, 2012), h. 275-276.
} 
paling sabar dan tabah menghadapi lapar, haus, kerja berat, dan kondisi-kondisi yang jelek. $^{52}$

\section{Kesimpulan}

Term pengetahuan biologi tidak dijumpai dalam ayat Alquran. Namun banyak ayat yang berkaitan dengan pengetahuan biologi sersebut. Pengetahuan biologi merupakan suatu ilmu yang mempelajari tentang makhluk hidup. Dan obyek kajiannya yaitu manusia, hewan dan tumbuh-tumbuhan. Di antara ayat-ayat yang berkaitan dengan pengetahuan biologi yaitu: Asal kejadian: QS. al-Anbiya : 30, QS. al-Nur: 45, QS. Shad: 71-72, QS. al-Insan: 2, Keanekaragaman dan klasifikasi: QS. Thaha: 53, QS. al-Hajj: 5, Reproduksi/berpasang-pasangan: QS. al-Syura: 11, QS. al-Hijr: 22, QS. Yasin: 36, Zoologi invertebrata: QS. alAnkabut: 41, QS. al-Syura: 29, Zoologi vertebrata: QS. al-Mulk: 19, Tingkah laku hewan: QS. al-Nahal: 68, Indra (kulit): QS. al-Nisa: 56, dan tubuh hewan (unta): QS. al-Ghasyiyah: 17.

Dengan adanya kajian ayat-ayat yang berkaitan dengan pengetahuan biologi, jelaslah bahwa di dalam Alquran ayat-ayatnya tidak ada satupun yang menghalangi kemajuan ilmu pengetahuan, bahkan sebaliknya mendorong untuk lebih maju lagi. Hal ini sangat bermanfaat bagi manusia. Bahwa manfaat adanya pengetahuan biologi, Allah swt. menciptakan hewan untuk kepentingan manusia, sehingga manusia sangat membutuhkan hewan untuk dijadikan konsumsi.

\section{Pustaka Acuan}

Almujahid, A. Thoha Husein \& Atho'illah Fathoni Alkhalil. Kamus Akbar Bahasa Arab (Indonesia-Arab). Jakarta: Gema Insani, 2013.

al-Suyuthi, Jalaluddin. Lubab al-Nuqul fi Asbab al-Nuzul, terj. Abdul Hayyie dkk. Sebab Turunnya Ayat Alquran. Jakarta: Gema Insani, cet. 1, 2008.

Sarwito, Departemen Pendidikan Nasional; Kamus Besar Bahasa Indonesia Pusat Bahasa. Jakarta: Gramedia, edisi 4, cet. 1, 2008.

Hamka, Tafsir Al-Azhar. juz I-II. Jakarta; PT Pustaka Panjimas 1983.

\footnotetext{
${ }^{52}$ Sayyid Quthb, Tafsir fi Zhilalil Quran di Bawah Naungan Alquran (Jakarta: Gema Insani Press, Jilid 12, cet. 2, 2008), h. 258.
} 
Syekh Abdul Halim Hasan Binjai, Tafsir Al-Ahkam. Cet.I Tahun 2006.

Muhammad bin Khaldun, Al-Allamah Abdurrahman. Mukaddimah Ibnu Khaldun, terj. Masturi Irham dkk. Jakarta: Pustaka al-Kautsar, cet. 3, 2013.

Muhammad, Akhsin Sakho dkk. Alquran Dan Tafsirnya. Jakarta: Widya Cahaya, Jilid 2, 2011.

Muhammad, Akhsin Sakho dkk. Alquran Dan Tafsirnya. Jakarta: Widya Cahaya, Jilid 5, 2011.

Muhammad, Akhsin Sakho dkk. Alquran Dan Tafsirnya. Jakarta: Widya Cahaya, Jilid 6, 2011.

Muhammad, Akhsin Sakho dkk. Alquran Dan Tafsirnya. Jakarta: Widya Cahaya, Jilid 7, 2011.

Muhammad, Akhsin Sakho dkk. Alquran Dan Tafsirnya. Jakarta: Widya Cahaya, Jilid 8, 2011.

Muhammad, Akhsin Sakho dkk. Alquran Dan Tafsirnya. Jakarta: Widya Cahaya, Jilid 9, 2011.

Muhammad, Akhsin Sakho dkk. Alquran Dan Tafsirnya. Jakarta: Widya Cahaya, Jilid 10, 2011.

Mustafa, Ahmad, Tafsir al-Maraghi, Kairo: Bab al-Halabi. Jld. 1, 1946.

al-Najjar, Zaglul. Sains dalam Hadis Mengungkap Fakta Ilmiah dai Kemukjizatan Hadis Nabi, terj. Zainal Abidin dkk. Jakarta: Amzah, cet. 1, 2011.

Quthb, Sayyid. Tafsir fi Zhilalil Quran di Bawah Naungan Alquran. Jakarta: Gema Insani Press, Jilid 10, cet. 2, 2008.

Quthb, Sayyid.. Tafsir fi Zhilalil Quran di Bawah Naungan Alquran. Jakarta: Gema Insani Press, Jilid 12, cet. 2, 2008.

Shihab, M. Quraish. Membumikan Alquran Fungsi dan peran Wahyu Dalam Kehidupan Masyarakat. Bandung: Mizan, Edisi 2, Cet. 1, 2013.

Shihab, M. Quraish. Tafsir al-Misbah Pesan, Kesan, dan Keserasian Alquran. Jakarta: Lentera Hati, Volume 2, Cet. 5, 2012.

Shihab, M. Quraish. Tafsir al-Misbah Pesan, Kesan, dan Keserasian Alquran. Jakarta: Lentera Hati, Volume 6, Cet. 5, 2012.

Shihab, M. Quraish. Tafsir al-Misbah Pesan, Kesan, dan Keserasian Alquran. Jakarta: Lentera Hati, Volume 7, Cet. 5, 2012. 
Shihab, M. Quraish. Tafsir al-Misbah Pesan, Kesan, dan Keserasian Alquran. Jakarta: Lentera Hati, Volume 8, Cet. 5, 2012.

Shihab, M. Quraish. Tafsir al-Misbah Pesan, Kesan, dan Keserasian Alquran. Jakarta: Lentera Hati, Volume 10, Cet. 5, 2012.

Shihab, M. Quraish. Tafsir al-Misbah Pesan, Kesan, dan Keserasian Alquran. Jakarta: Lentera Hati, Volume 11, Cet. 5, 2012.

Shihab, M. Quraish. Tafsir al-Misbah Pesan, Kesan, dan Keserasian Alquran. Jakarta: Lentera Hati, Volume 12, Cet. 5, 2012.

Shihab, M. Quraish. Tafsir al-Misbah Pesan, Kesan, dan Keserasian Alquran. Jakarta: Lentera Hati, Volume 14, Cet. 5, 2012.

Shihab, M. Quraish. Tafsir al-Misbah Pesan, Kesan, dan Keserasian Alquran. Jakarta: Lentera Hati, Volume 15, Cet. 5, 2012.

Tharayyahrah, Nadiah. Sains Dalam Alquran, terj. M. Zaenal Arifin dkk. Jakarta: Zaman, cet. 1, 2013.

Winansih, Varia. Pendidikan Ilmu-Ilmu Kealaman Dalam Hadis, dalam Hasan Asari, Hadis-Hadis Pendidikan Sebuah penelusuran Akar-Akar ilmu Pendidikan Islam. Bandung: Citapustaka Media Perintis, cet. 1, 2008.

Zaini,Hasan, Tafsir Tematik Ayat-ayat Kalam Tafsir Al-Maraghi. Jakarta: Pedoman Ilmu Jaya, 1997. 